American Journal of Environmental Sciences 6 (3): 244-248, 2010

ISSN 1553-345X

(C) 2010 Science Publications

\title{
Tartaric Acid Modified Rice Hull as a Sorbent for Methylene Blue Removal
}

\author{
${ }^{1}$ Siew-Teng Ong, ${ }^{2}$ Pei-Sin Keng, ${ }^{1}$ Ai-Wen Chong, ${ }^{3}$ Siew-Ling Lee and ${ }^{4}$ Yung-Tse Hung \\ ${ }^{1}$ Department of Chemical Science, Faculty of Science, University Tunku Abdul Rahman, \\ Jalan University, Bandar Barat, 31900 Kampar, Perak, Malaysia \\ ${ }^{2}$ Department of Pharmaceutical Chemistry, International Medical University, \\ No. 126, Jalan 19/155B, Bukit Jalil, 57000 Kuala Lumpur, Malaysia \\ ${ }^{3}$ Ibnu Sina Institute for Fundamental Science Studies, \\ University Technology Malaysia, 81310 Skudai, Johor Malaysia \\ ${ }^{4}$ Department of Civil and Environmental Engineering, \\ Cleveland State University, Cleveland, Ohio USA
}

\begin{abstract}
Problem statement: Improper dye discharge from various industries such as textile, paper, cosmetic and plastics into receiving streams can be one of the sources towards water pollution. The release of these effluents not only causes various disruptions in the ecosystems, but also poses hazard effect as most of the dyes are highly toxic, mutagenic and carcinogenic in nature. Approach: To prepare an inexpensive and efficient sorbent by chemically modifying rice hull for the removal of Methylene Blue (MB) which is predominantly used in coloring acrylic fiber. Batch experiments were carried out for the removal of MB from aqueous solution by using Tartaric Acid Modified Rice Hull (TARH). Parameters studied include effect of $\mathrm{pH}$, contact time, initial dye concentration and agitation rate and sorption isotherm. Results: From the results, the percentage uptake of MB increased with increasing contact time and agitation rate. Based on the linear regression correlation coefficient, $\mathrm{R}^{2}$, the system under study is more appropriately described by the pseudo-second order model. Maximum sorption capacity calculated from the Langmuir model is $25.0 \mathrm{mg} \mathrm{g}^{-1}$ for MB. Conclusion: The study has shown the effectiveness of TARH in the removal of $\mathrm{MB}$, a basic dye from synthetic solutions.
\end{abstract}

Key words: Adsorption, methylene blue, batch study, kinetics

\section{INTRODUCTION}

Chemical oxidation, chemical coagulation, biological treatment and photodegradation are some of the most commonly practiced processes for the removal of dyes from industrial wastewater. However, most of these methods suffer from some drawback such as high operational cost, generate secondary pollutants or unable to treat large quantities of wastes. Therefore, various biological and industrial by products have been investigated intensively for their ability to remove dye from aqueous solution as they can be obtained readily and are in great abundance. The utilization of these materials could also result in waste minimization.

Rice hull is generated as a waste during the first stage of rice milling, when rough rice or paddy rice is husked (husk is separated from the rest of the grain). It contains approximately $20 \%$ silica in combination with a large amount of the structural polymer, lignin. Ong et al.
(2009) reported that modifying rice straw with ethylenediamine resulted in enhancement of Congo Red removal. Rice straw treated with citric acid showed similar sorption enhancement (Gong et al., 2006). Rice hull which had a relatively low affinity for reactive dyes showed increased sorption capacity upon chemical modifications (Ong et al., 2010).

Sorption of dyes onto various sorbents demonstrated that the sorption capacities are affected by operational parameters such as $\mathrm{pH}$, contact time, initial dye concentration and particle size. In this study, we report the performance of tartaric acid modified rice hull under various conditions as a sorbent for Methylene Blue (MB).

\section{MATERIALS AND METHODS}

Sorbates: The cationic dye MB (Sigma-Aldrich) was used without further purification. Standard dye solution

Corresponding Author: Siew-Teng Ong, Department of Chemical Science, Faculty of Science,

University Tunku Abdul Rahman, Jalan University, Bandar Barat, 31900 Kampar, Perak, Malaysia 
of $1000 \mathrm{mg} \mathrm{L}^{-1}$ were prepared as stock solutions and subsequently diluted when necessary.

Sorbents: Rice hull was washed thoroughly with water to ensure the removal of dust and ash. It was then rinsed several times with distilled water and dried overnight in an oven at $50^{\circ} \mathrm{C}$. The dried rice hull was then ground to pass through a $1 \mathrm{~mm}$ sieve and labeled as unmodified rice hull.

Modification process: About $5 \mathrm{~g}$ grinded rice hull was mixed with $35 \mathrm{~m} \mathrm{~L}$ of $1.2 \mathrm{M}$ Tartaric Acid (TA). The mixture was stirred until homogenous and dried at $50^{\circ} \mathrm{C}$ overnight. The treated rice hull was subsequently washed with distilled water until neutral and dried overnight at $50^{\circ} \mathrm{C}$. The final product was labeled as Tartaric Acid Modified Rice Hull (TARH).

Batch experiments: The batch studies were carried out at room temperature $\left(25 \pm 2{ }^{\circ} \mathrm{C}\right)$ by mixing $0.1 \mathrm{~g}$ of TARH with $20.0 \mathrm{~mL} \mathrm{MB}$ solution in a centrifuge tube and shaken on an orbital shaker at 150 revolutions $\min ^{-1}(\mathrm{rpm})$ for $5 \mathrm{~h}$ unless otherwise stated. The reaction mixture was then centrifuged at $3000 \mathrm{rpm}$ for phase separation. All the batch experiments were carried out in duplicate and the results given are the means with a Relative Standard Deviation (RSD) of less than $5 \%$. Control experiments without sorbent was carried out to ascertain that the sorption was by the sorbent and not the wall of the container. The percentage of dye uptake (percent uptake) was calculated using the following equation:

Percent uptake $=\frac{\mathrm{C}_{\mathrm{o}}-\mathrm{C}_{\mathrm{t}}}{\mathrm{C}_{\mathrm{o}}} \times 100$

Where:

$\mathrm{C}_{\mathrm{o}}=$ The initial dye concentration $\left(\mathrm{mg} \mathrm{L}^{-1}\right)$

$\mathrm{C}_{\mathrm{t}}=$ The dye concentration $\left(\mathrm{mg} \mathrm{L}^{-1}\right)$ at any time

To examine the effect of $\mathrm{pH}$, the $\mathrm{pH}$ of the dye solution was adjusted to the values in the range of 3-9 using $0.1 \mathrm{M}$ hydrochloric acid $(\mathrm{HCl})$ and $0.1 \mathrm{M}$ sodium chloride $(\mathrm{NaOH})$ prior to the experiment. Effect of contact time was studied by shaking the sorption mixture at various predetermined time intervals and analyzes the dye concentration at the end of contact time. Sorption isotherms were obtained by varying the dye concentrations from $20-90 \mathrm{mg} \mathrm{L}^{-1}$. The effect of agitation was carried out by varying the agitation rate from 50-200 rpm.

Techniques: The dye concentration was analyzed using a Perkin Elmer Lambda 35 UV-vis spectrophotometer.
All measurements were made at the wavelength corresponding to maximum absorption for $\mathrm{MB}$, $\lambda_{\max }=665 \mathrm{~nm}$. Dilutions were carried out when measurement exceeded the linearity of the calibration curve.

\section{RESULTS}

Figure 1 shows the comparative uptake of MB by unmodified and modified rice hull. The effect of $\mathrm{pH}$ on the uptake of MB by TARH is shown in Fig. 2. Time course experiments on MB sorption are shown in Fig. 3. Table 1 show the correlation coefficients based on pseudo first and second order kinetic models. Langmuir and Freundlich constant for MB sorption were included in Table 2. The variation of MB uptake with agitation rate is shown in Fig. 6.

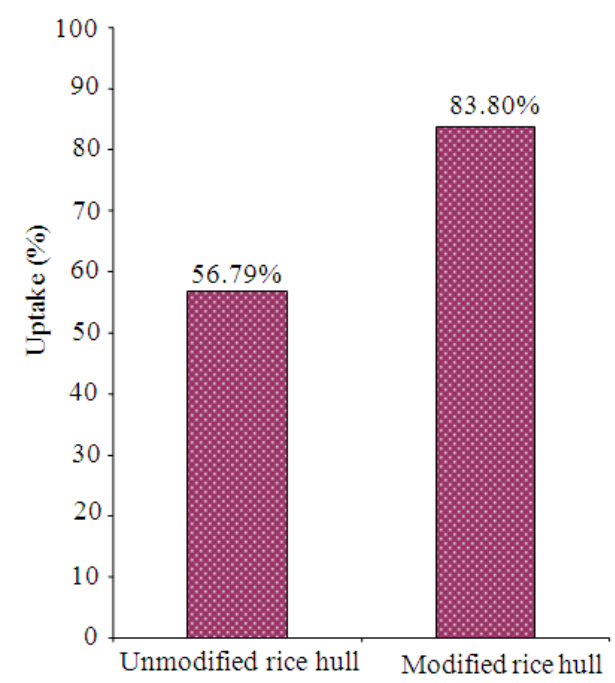

Fig. 1: Comparative studies of unmodified and modified rice hull

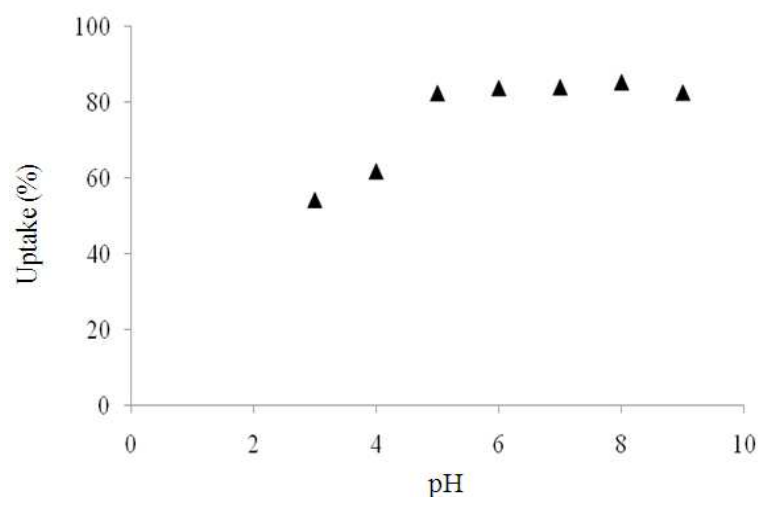

Fig. 2: Effect of $\mathrm{pH}$ on the sorption of MB by TARH 


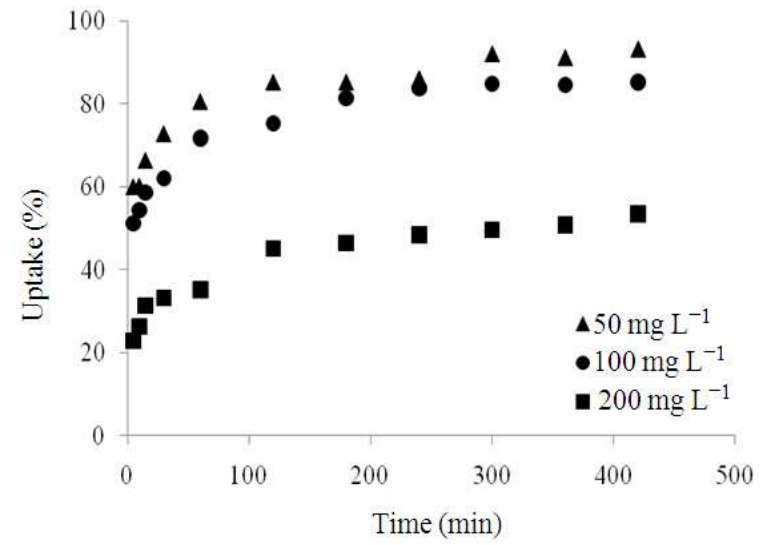

Fig. 3: Effect of initial dye concentrations and contact time on sorption of MB by TARH

Table 1: Pseudo-first and pseudo-second order kinetic correlation coefficients for different initial MB concentrations

\begin{tabular}{lll}
\hline $\begin{array}{l}\text { Initial MB } \\
\text { concentration }\left(\mathrm{mg} \mathrm{L}^{-1}\right)\end{array}$ & $\begin{array}{l}\text { Pseudo-first } \\
\text { order kinetic }\left(\mathrm{R}^{2}\right)\end{array}$ & $\begin{array}{l}\text { Pseudo-first } \\
\text { order kinetic }\left(\mathrm{R}^{2}\right)\end{array}$ \\
\hline 50 & 0.9005 & 0.9989 \\
100 & 0.8633 & 0.9992 \\
200 & 0.6982 & 0.9997 \\
\hline
\end{tabular}

Table 2: Langmuir and Freundlich isotherm model constants and correlation coefficients for sorption of MB by TARH

Langmuir isotherm Freundlich isotherm

\begin{tabular}{llllll}
$\mathrm{N}^{*}\left(\mathrm{mg} \mathrm{g}^{-1}\right)$ & $\mathrm{K}_{\mathrm{L}}\left(\mathrm{L} \mathrm{mg}^{-1}\right)$ & $\mathrm{R}^{2}$ & $\mathrm{~K}_{\mathrm{F}}$ & $1 \mathrm{n}^{-1}$ & $\mathrm{R}^{2}$ \\
\hline 24.63 & 0.1733 & 0.982 & 4.436 & 0.546 & 0.975
\end{tabular}

\section{DISCUSSION}

Comparison study: The comparative uptake of MB by unmodified and modified rice hull at the natural $\mathrm{pH}$ of the dye solutions is shown in Fig. 1. It is apparent that the sorption of MB was enhanced when TARH is being used as the sorbent. The presence of carboxyl groups in TARH is believed to be primarily responsible for the sorption of MB. Previous investigations have also postulated that the sorption of positively charged species is due to the presence of binding sites such as carboxyl and hydroxyl groups on the surface (Tang et al., 2003; Munaf and Zein, 1997; Wong et al., 2003).

Effect of pH: It is well known that $\mathrm{pH}$ of the solution is one of the prime factors influencing the sorption's efficiency of a system. Fig. 2 shows the MB sorption increase with increasing $\mathrm{pH}$ value. At low $\mathrm{pH}$, the removal of $\mathrm{MB}$ was suppressed by $\mathrm{H}^{+}$ions that surrounded the surface of the sorbent hindering the approach of MB to the carboxylate groups present on the surface of TARH. The protonation of carboxylate groups would also reduce the MB sorption. With increasing $\mathrm{pH}$, sorption became favorable due to the deprotonation of carboxyl groups (-COO), resulting in more sorption sites available for binding with MB. This phenomenon favors the sorption of positively charged dye due to electrostatic attraction (Namasivayam et al., 2001).

Effect of initial dye concentration and contact time: The rates of $\mathrm{MB}$ sorption at various initial concentrations $\left(50,100\right.$ and $\left.200 \mathrm{mg} \mathrm{L}^{-1}\right)$ is shown in Fig. 3. The percentage of sorption decreased with increasing solution concentration while the amount of dye sorbed increased. The fast uptake at the beginning may be attributed to the rapid attachment of the dye molecules to the surface of the sorbent and the following slower sorption to intraparticle diffusion (Fawzi et al., 2003). In order to gain important insight on the reaction pathways and the sorption mechanisms, experimental data were fitted into the following equations (Langergren and Svenska, 1898; Ho and McKay, 1999; 2000):

$$
\log \left(q_{e}-q_{t}\right)=\log q_{e}-k_{1} t / 2.303(\text { pseudo }- \text { first order })
$$

and

$\mathrm{t} / \mathrm{q}_{\mathrm{t}}=1 / \mathrm{h}+\mathrm{t} / \mathrm{q}_{\mathrm{e}}($ pseudo - second order $)$

Where:

$\mathrm{q}_{\mathrm{e}} \quad=$ The amount of dyes sorbed at equilibrium $\left(\mathrm{mg} \mathrm{g}^{-1}\right)$

$\mathrm{q}_{\mathrm{t}}=$ The amount of dyes sorbed at time $\mathrm{t}$ $\left(\mathrm{mg} \mathrm{g}^{-1}\right)$

$\mathrm{k}_{1} \quad=$ The rate constant of pseudo-first order sorption $\left(1 \mathrm{~min}^{-1}\right)$

$\mathrm{h}\left(\mathrm{k}_{2} \mathrm{q}_{\mathrm{e}}^{2}\right)=$ The initial sorption rate $\left(\mathrm{mg} \mathrm{g}^{-1} \mathrm{~min}^{-1}\right)$

$\mathrm{k}_{2} \quad=$ The rate constant of pseudo- second order kinetics $\left(\mathrm{g} \mathrm{mg}^{-1} \mathrm{~min}^{-1}\right)$

It was found that application of pseudo-second order model provides better correlation of the experimental data than the pseudo-first order model for the different systems studied (Table 1). It thus appears that the system under study is more appropriately described by the pseudo- second order model which was based on the assumption that the rate limiting step may be chemical sorption or chemisorptions involving valency forces through sharing or exchange of electron between sorbent and sorbate (Ho and McKay 2000). 
Am. J. Environ. Sci., 6 (3): 244-248, 2010

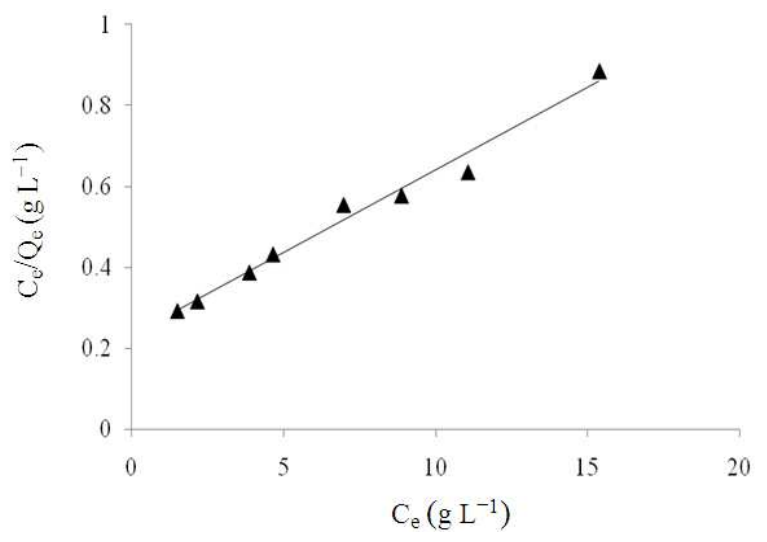

Fig. 4: Langmuir isotherm on sorption of MB by TARH

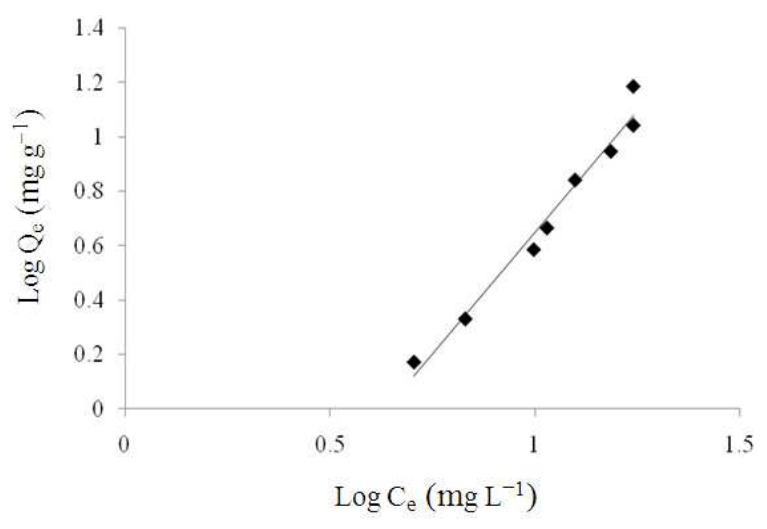

Fig. 5: Freundlich isotherm on sorption of MB by TARH

Sorption isotherm: The sorption data in the present study was fitted into Langmuir and Freundlich isotherm models. The linear plots of $\mathrm{C}_{\mathrm{e}} / \mathrm{Q}_{\mathrm{e}}$ versus $\mathrm{C}_{\mathrm{e}}$ and $\log \mathrm{Q}_{\mathrm{e}}$ versus $\log \mathrm{C}_{\mathrm{e}}$ are shown in Fig. 4 and 5 respectively. Table 2 gives the coefficients for the linearized forms of the isotherm models for sorption of MB on TARH. Although these two models are based on different assumptions: Langmuir model implies monolayer coverage and constant sorption energy while Freundlich model deals with physicochemical sorption on heterogeneous surfaces, both Langmuir and Freundlich models appear to provide reasonable fittings for the sorption data of MB on TARH.

Applicability of both isotherms to sorption of dyes by agricultural wastes, activated carbons prepared from wastes and treated spent bleaching earth have been reported previously (Ong et al., 2007; Malik, 2003; Lee et al., 1999).

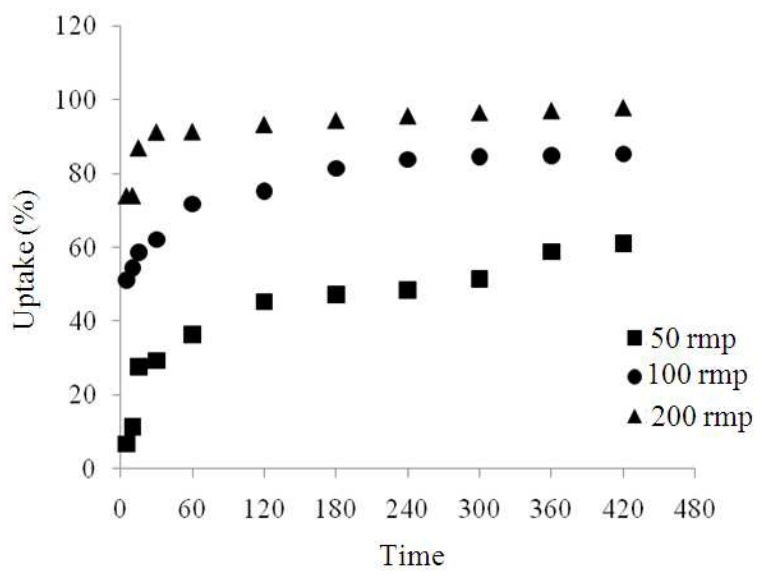

Fig. 6: Effect of agitation rate on sorption of MB by TARH

Effect of agitation rate: The experimental results obtained from a series of contact time studies for the sorption of MB onto TARH in which the degree of agitation was varied from 50-200 rpm are presented in the Fig. 6. For the first $5 \mathrm{~min}$, the percentage uptake increased from $6.74-73.99 \%$ as the agitation rate increased from 50-200 rpm and gradually attained equilibrium after $3 \mathrm{~h}$. The results suggests that increasing agitation rate decreases the film resistance to mass transfer surrounding the sorbent particles thus increasing sorption of dye molecules.

\section{CONCLUSION}

The study has shown the effectiveness of TARH in the removal of $\mathrm{MB}$, a basic dye from synthetic solutions. The equilibrium data conform to both Langmuir and Freundlich isotherms. Analysis of data indicates that pseudo-second order kinetic model provided a better correlation of the experimental data than pseudo-first order model. As rice hull is readily available in great abundance in Malaysia, it can be considered as an attractive alternative to the more expensive technologies used in wastewater treatment containing dye.

\section{ACKNOWLEDGEMENT}

Financial support from the international foundation of science, Stockholm, Sweden and the organization for the prohibition of chemical weapons, The Hague, The Netherlands via grant no. W/4368-1 as well as the lab facilities provided by University Tunku Abdul Rahman (UTAR) is acknowledged. 


\section{REFERENCES}

Fawzi, B., S. Al-Asheh and L. Al-Makhadmeh, 2003. Evaluation of the use of raw and activated date pits as potential adsorbents for dye containing waters. Process Biochem., 39: 193-202. DOI: 10.1016/S0032-9592(03)00065-7

Gong, R.M., Y.B. Jin and F.Y. Chen, 2006. Enhanced malachite green removal from aqueous solution by citric acid modified rice straw. J. Hazard. Mater., 137: 865-870. DOI: 10.1016/j.jhazmat.2006.03.010

Ho, Y.S. and G. McKay, 1999. Pseudo second order model for sorption process. Process Biochem., 34: 451-465. DOI: 10.1016/S0032-9592(98)00112-5

Ho, Y.S. and G. McKay, 2000. The kinetics of sorption of divalent metals ions onto sphagnum moss peat. Water Res., 34: 735-742. DOI: 10.1016/S00431354(99)00232-8

Langergren, S. and B.K. Svenska, 1898. Zur theorie der sogenannten adsorption geloester stoffe. Veternskapsakad Handlingar, 24: 1-39.

Lee, C.K., K.S. Low and P.Y. Gan, 1999. Removal of some organic dyes by acid treated spent bleaching earth. Environ. Technol., 20: 99-104. DOI: 10.1080/09593332008616798

Malik, P.K., 2003. Use of activated carbons prepared from sawdust and rice-husk for adsorption of acid dyes: A case study of acid yellow 36. Dyes Pigments, 56: 239-249. DOI: 10.1016/S01437208(02)00159-6

Munaf, E. and R. Zein, 1997. The use of rice husk for removal of toxic metals from waste water. Environ. Technol., 18: 359-362. DOI: 10.1080/09593331808616549
Namasivayam, C., R. Radhika and S. Suba, 2001. Uptakes of dyes by a promising locally available agricultural solid waste: coir pith. Waste Manage., 21: 381-387. DOI: 10.1016/S0956053X(00)00081-7

Ong, S.T., C.K. Lee and Z. Zainal, 2007. Removal of basic and reactive dyes using ethylenediamine modified rice hull. Bioresour. Technol., 98: 2792-2799. DOI: 10.1016/j.biortech.2006.05.011

Ong, S.T., E.H. Tay, S.T. Ha, W.N. Lee and P.S. Keng, 2009. Equilibrium and continuous flow studies on the sorption of Congo red using ethylenediamine modified rice hulls. Int. J. Phys. Sci., 4: 683-690. http://www.academicjournals.org/IJPS/abstracts/abstr acts/abstracts2009/November/Ong\%20et\%20al.htm

Ong, S.T., P.S. Keng and C.K. Lee, 2010. Basic and reactive dyes sorption enhancement of rice hull through chemical modification. Am. J. Applied Sci., 7 : 447-452. http://www.scipub.org/fulltext/ajas/ajas74447452.pdf

Tang, P.L., C.K. Lee, K.S. Low and Z. Zainal, 2003. Sorption of $\mathrm{Cr}$ (VI) and $\mathrm{Cu}$ (II) in aqueous solution by ethylenediamine modified rice hull. Environ. Technol., 24: 1243-1251. DOI: 10.1080/09593330309385666

Wong, K.K., C.K. Lee, K.S. Low and M.J. Haron, 2003. Removal of $\mathrm{Cu}$ and $\mathrm{Pb}$ from electroplating wastewater using tartaric acid modified rice husk. Process Biochem., 39: 437-445. DOI: 10.1016/S0032-9592(03)00094-3 